\title{
DE MÁQUINA A PROYECTO: EL CUERPO EN EL NUEVO ESPÍRITU DEL CAPITALISMO
}

\section{SINCE MACHINE TO PROJECT: THE BODY IN THE NEW SPIRIT OF CAPITALISM}

\author{
Nairbis Sibrian ${ }^{1}$ \\ nairbiss@gmail.com
}

\begin{abstract}
Fecha de recepción: 18 de setiembre de 2015 - Fecha de aceptación: 5 de julio de 2016
\end{abstract}
“Entonces, ¿qué hemos de elegir? ¿El peso o la levedad?”

Parménides

\begin{abstract}
Resumen
Si Foucault advirtió un cuerpo producido por el disciplinamiento de instituciones, es decir, vislumbró un cuerpo como máquina; Conrad, entre otros, ve cómo éste deviene en un proyecto en el mercado de la salud. Este desplazamiento cobra sentido bajo la perspectiva del nuevo espíritu del capitalismo que acusan Boltanski y Chiapello en su obra, donde la corporalidad en lugar de permanecer en circuitos cerrados experimenta la apertura y conexión en un mundo global, esto es, de máquina para el trabajo el cuerpo se transforma en una proyección de deseos, en una red. Sin embargo, esta modalidad no supone la desaparición por completo de la máquina corporal sino más bien su refinamiento. Con el propósito de indagar acerca de este transitar se realiza un recorrido sobre el lugar del cuerpo en el campo médico a partir de las críticas que su dominio ha generado en diferentes enfoques y su relación con los cambios organizacionales y económicos de la sociedad.
\end{abstract}

Palabras claves: Sociología del cuerpo, Medicina, Tecnología, Mercado, Cambios organizacionales

\begin{abstract}
If Foucault warned a body produced by the disciplining of institutions, that is, he glimpsed a body as a machine; Conrad, and others, sees how the body becomes project in the healthcare market. This shift makes sense from the perspective of the new spirit of capitalism which accuse Boltanski and Chiapello in his work, where corporeality rather than remain in closed circuit, experience opening and connection in a global world, that is to say, since machine to work the body becomes a projection of desires, on a network. However, this method does not involve the complete disappearance of the body machine but rather it refinement. With the purpose to inquire about this move a review will take place of the body in the medical field from criticism that its domain has generated different approaches and their relationship with organizational and economic changes in society.
\end{abstract}

Key words: Body sociology, Medicine, Technology, Market, Organizational changes.

1 Doctorado en Sociología, Universidad Alberto Hurtado. Becaria Conicyt 2015. 


\section{Introducción}

El cuerpo ha sido sumamente relevante para la teoría social. Desde diversas disciplinas es visto como un elemento decisivo para el pensamiento moderno, tanto de la sociedad como del individuo. Numerosos autores lo han estudiado sea como un espacio material donde se evidencian transformaciones y estancamientos; sea como una situación (Beauvoir, 1998), que porta gustos distintivos de una clase (Bourdieu, 2002), signos de diferencia y estigma (Goffman, 2009), o cuyos usos reflejan más bien una dimensión social (Bolstanski, 1975). Tales posiciones, entre otras, señalan al cuerpo como un ente dotado de discurso, con disputas provenientes desde diversos ámbitos y cuyo sentido no permanece absorto a los cambios epocales. En este sentido, la perspectiva antropológica señala que las actuales concepciones del cuerpo están vinculadas al ascenso del individualismo, la emergencia del pensamiento racional y el auge de la medicina como el saber oficial sobre éste (Le Breton, 2002).

Precisamente, es el campo de la medicina y la salud donde, a raíz de las transformaciones globales, los cuerpos son progresivamente virtualizados, permitiendo nuevas dimensiones interpretativas. En principio, por "el uso creciente de nuevas tecnologías de visualización asociado al desarrollo de anatomías clínicas virtuales" (Ortega, 2010, p.16), luego por el desarrollo de identidades vinculadas a los servicios de cuidado y asistencia vía dispositivos tecnológicos (Castillo y Tirado, 2012), y finalmente gracias al mejoramiento genético y el desarrollo de técnicas para la modificación celular y planificación corporal (Conrad, 2007).

Así, el cuerpo pareciera haber transitado de un paradigma de disciplinamiento institucional y clausura a un paradigma reticular de modelación, autogestión y apertura donde la creación, modificación y adaptabilidad podrían haberse transformado en sus nuevas características. Sin embargo, aún se discute si esta nueva modalidad no supondría también nuevas formas de sujeción pues, pese a las numerosas tentativas de cambiarle, desde el físiculturismo, las cirugías plásticas o la biotecnología, que lo convierten en un espacio de creación (Ortega, 2010), éste también puede ser el lugar de lo abyecto donde si bien los límites impuestos pueden ser transgredidos (Butler, 2002) es, probablemente, todavía un espacio de control (Deleuze, 2005).

Con el propósito de indagar acerca de este transitar se realizará un recorrido sobre el lugar del cuerpo en el campo médico a partir de las críticas que su dominio ha generado en épocas distintas. Por un lado, Michel Foucault cuya crítica versa sobre las instituciones y el disciplinamiento de los cuerpos y, por otro, Peter Conrad quien critica a las empresas que gestionan la salud y producen al cuerpo en la actualidad, para, posteriormente, relacionar tales transformaciones con el nuevo espíritu del capitalismo (Bolstanski y Chiapello, 2002) y polemizar esta hipótesis desde diversos registros. Por ello, la pregunta de investigación es ¿qué incidencia han tenido los cambios organizacionales y económicos de la sociedad en el estatuto del cuerpo en la medicina?

\section{1- Cuerpo, salud y modernidad}

La modernidad ha estado marcada por el auge de la filosofía mecanicista, impulsada por los trabajos de Copérnico, Bruno, Kepler y Galileo. Desde entonces la sociedad se desplaza del mundo especulativo al de la precisión. Para Le Breton (2002) este movimiento constituye el paso de un modo de inteligibilidad a otro, más preciso respecto a ciertos criterios culturales que introducen con fuerza nuevas nociones de medida, exactitud, rigor, entre otras.

Esta metamorfosis del mundo occidental, que comienza en el siglo XVII y se prolonga hasta nuestros días, conlleva una eficacia cada vez mayor en el control de la naturaleza y de aquello que constituye su proyecto: el hombre, como el paroxismo de un modelo pratriarcal y heteronormativo, y en consecuencia también altera las representaciones del cuerpo. Con esta nueva forma de pensar, el fundamento religioso pierde fuerza y se adquiere la medida de lo humano para todas las cosas. Pero si el mundo tiene dicha medida, es a condición de racionalizar todo lo existente y abandonar las emociones al campo de lo ilusorio. Si bien, tal y como señala Le Breton (2002) las nuevas formas de conocimiento 
liberan a cierta parte de la sociedad de su fidelidad a las tradiciones, también es cierto que le sujetan a nuevos valores. De ahora en adelante se despliega toda la energía humana para transformar la naturaleza y conocer el interior invisible del cuerpo.

Las disciplinas y las prótesis correctoras se multiplican y con ello, la técnica y la ciencia se inscriben en el camino de la superación del cuerpo, mientras la pregunta que articula todo su andamiaje es ¿cómo hacer del cuerpo un objeto fiable, digno de procedimientos técnicos y científicos? La consigna es corregir el cuerpo, hacer de él una mecánica, asociarlo con la idea de máquina, para escapar de "la insoportable levedad del ser" como diría Milan Kundera (1996).

Pero esta misma idea llevará a la sociedad a superar el paradigma de la máquina en tanto objeto a reparar, por ende defectuoso, y le conducirá por el sendero de la creación de un cuerpo a su justa medida. En este trayecto la acompañará el saber anátomo-fisiológico en el que se apoya la medicina moderna, y tal y como lo advierte Le Breton (2002) la preocupación por la salud y por la forma [del cuerpo] se convertirán en las claves de la modernidad.

\section{1- La idea del cuerpo en Foucault}

La crítica a la modernidad de Foucault advierte el desplazamiento de una episteme clásica a una episteme moderna donde el saber sufrió una alteración que imposibilitaría de ahora en adelante la separación "entre el sujeto que conoce y el objeto de conocimiento" (Foucault, 2008a, p.267). Ocasionando, además, en el nivel arqueológico, la sustitución del saber por la producción, esto es, que por un lado aparecen nuevos objetos cognoscibles y, por otro, nuevos conceptos y métodos.

Según este registro, en la episteme clásica era imposible dominar los cuerpos por medio de un conocimiento absoluto, se les dominaba sólo por la fuerza y el castigo. Sin embargo, la experiencia que surge en la modernidad aloja el descubrimiento de la finitud, "no ya en el interior del pensamiento de lo infinito, sino en el corazón mismo de estos contenidos" (Foucault, 2008a, p.329) que le son dados como formas concretas de la existencia finita. Por ello, el hombre, heteronormativo y patriarcal, experimenta su cuerpo como un terreno ambiguo, cuya espacialidad propia e irreductible se articula, no obstante, sobre el ámbito de las cosas.

Así, el cuerpo se presenta conceptualizado por una mirada abierta sobre sus cualidades que se vuelve atenta a todas sus modulaciones (Foucault, 2008b, p.37). Y es que junto con el desplazamiento hacia la episteme moderna, Foucault también advierte el surgimiento de nuevas técnicas disciplinarias de las instituciones cuyo resultado es un cuerpo producido bajo ciertos regímenes de verdad, donde el castigo ya no se da de forma dolorosa. De este modo, Foucault advierte que el ejercicio del poder no se efectúa en términos de propiedad sino como estrategia y sus efectos de dominación no son atribuibles a una apropiación ni a ninguna entidad "sino a disposiciones, a maniobras, a tácticas, a técnicas, a funcionamientos" (Foucault, 2008c, p.36), es decir, a una red de relaciones siempre tensas en torno al cuerpo.

Este es el momento en el que nace un arte del cuerpo humano que no se centra sólo en sus habilidades ni en hacer más pesada su sujeción, sino que busca un perfeccionamiento del "vínculo que, en el mismo mecanismo, lo hace tanto más obediente como más útil, y viceversa” (Foucault, 2008c, p.160). Se trata del inicio del refinamiento de las técnicas de control del cuerpo. La visualización de esta lógica supone el abandono de la hipótesis represiva, de las oscuras maquinaciones de naturaleza conspirativa provenientes de aquellos que detentan el poder, pues advierte un método mucho más sutil, más inteligente y probablemente más perverso que pasaba del castigo a la disciplina ${ }^{2}$ y que siempre buscará un modo más idóneo para controlar.

2 La disciplina produce cuerpos ejercitados y dóciles. La disciplina aumenta las fuerzas del cuerpo (en términos de utilidad económica) y disminuye esas mismas fuerzas (en términos de obediencia política). En una palabra: disocia el poder del cuerpo; por una parte, hace de este poder una "aptitud", una "capacidad" que trata de aumentar, y cambia por otra parte la energía, la potencia que de ello podría resultar, y la convierte en una relación de sujeción estricta. (Foucault, 2008c, p.160) 


\section{2- El cuerpo como máquina}

De acuerdo con Fuster (2013), Foucault identificó dos series de mecanismos de poder íntimamente ligados en los que se configura el vuelco de la política sobre la vida o biopolítica, la primera de ellas fue llamada anatomopolítica, la cual concibe a la disciplina como una tecnología de poder centrada en la docilización y potenciación del cuerpo para integrarle en los sistemas de control. Mientras, la segunda se refiere a una biopolítica de la población, a una mecánica de lo viviente, enfocada en la noción cuerpo-especie que dará origen al interés del Estado y también del mercado por una serie de procesos biológicos.

Así, la idea del cuerpo como máquina en Foucault es el resultado de esta objetivación de la vida, donde la relación cuerpo y saber médico está orientada a la solución de problemas económicos. No obstante, para que esto ocurriera fue necesario que el cuerpo se socializará por vía de cierta tecnología, la cual se produjo en coordinación con las formas de desarrollo de la medicina en diversos contextos que van de la medicina de Estado en Alemania, a la medicina urbana en Francia y, finalmente, la medicina laboral en Inglaterra (Foucault, 1996). Cada uno de estos modelos procura medicalizar a la población por razones distintas (para la guerra, la ciudad y el trabajo) en las que el cuerpo es el motor.

Del mismo modo, este recorrido histórico se produce a la par de otro fenómeno que Foucault (1996) llama despegue médico, que no es otra cosa que el desarrollo del sistema médico y su aumento progresivo de poder sobre el cuerpo, que si bien en un principio velaba por el idóneo estado de la máquina corporal luego sufre transformaciones a la par con los cambios organizacionales de la sociedad, y supondrá tres puntos importantes: la biohistoria, la medicalización y la economía de la salud.

Por otro lado, en el paradigma disciplinar la biohistoria alude al papel de la medicina en la generación de mecanismos de adaptación, desarrollo de resistencias, así como medidas de higiene que promovieron la evolución somática de la especie. A partir de entonces, se abre una nueva dimensión de posibilidades que signaron el desarrollo del sistema médico y el modelo seguido por el auge médico sanitario en Occidente, entre las que se encuentra la emergencia de un campo de saber que trabaja a nivel de la propia vida y de sus acontecimientos fundamentales con implicaciones profundas entre la vida y la historia.

La articulación de estas investigaciones con la ampliación institucional de la salud produjo el segundo paso del despegue de la medicina occidental, llamado por Foucault (1996) medicalización. Allí, la existencia, conducta y comportamiento se vieron englobados progresivamente en una red “cada vez más densa y más amplia que cuanto más funciona menos se escapa de la medicina" (1996, p.86) y que se orquesta con la emergencia de una nueva economía del cuerpo y la salud. En este sentido, la medicalización refiere al surgimiento de una red de instituciones médicas de las que el cuerpo humano no puede escapar y que supone no sólo los hospitales, consultorios o farmacias sino toda la organización de la vida.

Esta nueva economía constituye el tercer último engranaje de las transformaciones vislumbradas por Foucault en el campo de la medicina y comprende la integración del mejoramiento, los servicios y el consumo de salud en el desarrollo económico de las sociedades más privilegiadas. La medicina social inglesa es ejemplo de ello, y por ende fue la que se replicó por vincular tres cosas: la asistencia médica del pobre, el control de la salud de la fuerza laboral y la indagación general de la salud pública, protegiendo a la clase alta de los peligros generales. Pero, además, posibilitó la emergencia de tres sistemas de salud coexistentes: una medicina asistencial dedicada a los pobres, una medicina administrativa encargada de los problemas generales (como las vacunas y epidemias); y una medicina privada, donde se producirán casi siempre los adelantos tecnológicos y que benefician a quienes tengan medios para pagarla.

En el recorrido a transitar estos tres puntos no desaparecen, sino que se resitúan, acomodan y perfeccionan, cuyo primer desplazamiento es el derecho a la salud. 


\section{3- De la máquina corporal al derecho a la salud}

Si bien desde el siglo XVIII una de las funciones del Estado era garantizar una óptima condición física de los ciudadanos, tras la primera guerra mundial y sus embates la salud se transforma en un derecho. Entre 1940 y 1950, ya no es el cuerpo, ni la enfermedad lo que se debe atender sino la salud, pero además, ésta se transforma en objeto de preocupación no sólo para los países sino para los individuos, es decir, el derecho a mantener el cuerpo en buena salud se convierte en objeto de la propia acción estatal y con ello, explica Foucault (1996), se invierten los siguientes términos: "el concepto del individuo en buena salud para el Estado se sustituye por el del Estado para el individuo en buena salud" (p.68).

También destaca que no se trata sólo de una inversión en el derecho sino del nacimiento de lo que podría denominarse una nueva moral del cuerpo que, si bien comienza con el concepto de limpieza y salubridad, esto es, "la higiene se instala como centro de todos los dictámenes morales sobre la salud" (Foucault, 1996, p.68), rápidamente se desplazará hacia el bienestar y la prevención como un deseo tanto de los estados como de los individuos que conforman la población.

Es así como la salud entra en el campo de la macroeconomía y a partir de entonces su presencia o ausencia supone una variable en el presupuesto estatal. Además, por mediación de la salud, de las enfermedades y de la manera de cubrir las necesidades de salud se trata de proceder a cierta redistribución económica. Sin embargo, explica Foucault (1996) que esta redistribución ya no dependería del presupuesto sino del sistema de regulación y cobertura económica de la salud y las enfermedades. De este modo, el cuerpo, por vía de la salud y la enfermedad, se convierten en instrumento de socialización de los individuos.

La salud se vuelve una herramienta social, un conjunto de relaciones y vínculos que dará como resultado la formulación de un nuevo derecho, una nueva moral, una nueva economía y política del cuerpo que, posteriormente, se intensificará con "la posibilidad de modificar incluso el armamento genético de las células [que] no sólo afecta al individuo o su descendencia sino que a toda la especie" (Foucault, 1996, p.74) y que abrirá un mercado enorme para las agencias de cálculo que operan en el ámbito de la medicina.

\section{4- Nueva economía de la salud}

Si bien al principio se recurrió a la medicina como a un instrumento de mantenimiento y reproducción de la fuerza laboral para el funcionamiento de la sociedad moderna, en la actualidad la medicina entronca con la economía por otra vía: "no simplemente porque es capaz de reproducir la fuerza de trabajo sino porque puede producir directamente riqueza en la medida en que la salud constituye un deseo para unos y un lucro para otros" (Foucault, 1996, p.80), hecho que la relaciona con otra forma de gubernamentalidad.

Cuando la salud se convirtió en objeto de consumo; en un producto que puede ser fabricado por laboratorios farmacéuticos, gestionado por médicos y comprado por posibles y reales enfermos; entonces, adquirió importancia económica y se introdujo en el mercado. En ese momento, se produce una relación estrecha, incluso de performatividad (Callon, 1998) entre el discurso de la salud, la producción de pensamiento científico en torno a ella y la morfología de las relaciones económicas asociadas a la misma.

Entonces, el cuerpo deviene gestionado por una red de medicalización y doblemente introducido en el mercado: "en primer lugar en tanto que cuerpo salariado, cuando el hombre vendía su fuerza de trabajo y, en segundo lugar por intermedio de la salud". (Foucault, 1996, p.81). Se trata de la emergencia de un mercado que no necesariamente está vinculado con necesidades reales. Al respecto, Foucault (1996) cita los aportes de Charles Levinson quien, en un estudio sobre la producción de salud en 1964 en Europa, indica que al aumentar en un $1 \%$ el consumo de servicios médicos, el nivel de mortalidad 
descendió en apenas un $0,1 \%$ (p.81); lo cual revela que el consumo de salud no necesariamente es proporcional con la prolongación de la vida.

Tal paradoja - el hecho que el nivel de consumo de salud no tenga mayores impactos respecto al nivel de vida (morbilidad y mortalidad) - sin duda encuentra explicación en el surgimiento del dispositivo "multifacético y diversificado del mercado" (Callon, 1998, p.66), pues desde que la salud y el cuerpo humano son objeto de cálculo se produce una estrategia de gestión que los transforma a ambos, cuerpo y salud, en mercancía. Explica Callon (1998) que para transformar algo en una mercancía y dos agentes en un vendedor y un consumidor es necesario cortar los lazos entre la cosa y los otros objetos o seres. Se debe descontextualizar, disociar y separar para que los actores estén desenredados de vínculos y nuevamente introducidos en una red de mercado simplemente como compradores o proveedores. Justamente, esto es lo que hacen las estrategias de marketing apoyadas por un vasto sistema contable, compuesto de herramientas, procedimientos de cálculo y competencias que de alguna manera contribuyen al disciplinamiento de comportamientos y decisiones.

Surge, de hecho, una circulación de objetos y hasta órganos, descontextualizados, en torno a la salud, donde el cuerpo se planifica, crea y/o modifica. No obstante, lo crucial es que - pese a los augurios de emancipación y apuestas por la libertad, que abren amplio debate en diversos campos ${ }^{3}$ - el sujeto pudiera verse envuelto en una nueva red que lo produce, ya no como máquina, pero sí como la proyección de un ideal o deseo sujeto a la lógica mercantil.

\section{2- La idea de proyecto en el nuevo espíritu del capitalismo}

Tal parece que las críticas realizadas por Foucault $(1996,2008)$ a la episteme moderna y el disciplinamiento de los cuerpos, así como las de Ilich (1975) sobre la medicalización de la vida fueron realmente tomadas en cuenta por las agencias calculadoras del mercado (Callon, 1998) y desenredaron el cuerpo y sus órganos del sistema de control institucionalizado de la salud para reintroducirlo en una nueva red de intercambios, puesto que en el nuevo espíritu del capitalismo advertido por Boltanski y Chiapello (2002) se produce un vuelco en las formas de disciplinamiento de los comportamientos y el cuerpo ya no está sujeto a una estructura sino más bien inmerso en una red.

La hipótesis central de Boltanski y Chiapello (2002) es que el capitalismo tuvo la capacidad de integrar las críticas que se produjeron a partir de los acontecimientos de mayo de 1968, las cuales realizaban un llamamiento a la creatividad, al placer y a una liberación que afectase a todas las dimensiones de la existencia, donde sin duda el cuerpo era crucial, resituándolas ahora a favor del sistema.

Este movimiento ha ido dibujándose al compás de las “innovaciones organizativas, las invenciones técnicas y las modalidades de gestión que han ido sucediéndose desde la década de 1980" (Boltanski y Chiapello, 2002, p.153). Los autores sostienen que se trata de un segundo espíritu del capitalismo cuyos dispositivos han sido puestos en tela de juicio, modificados, transformados, suprimidos o reemplazados, logrando que surja la necesidad de dotarse de una nueva representación del mundo económico, esto es, nuevas formas de éxito y nuevas reglas de juego en el mundo económico a las que las personas tienden a ajustarse.

De tal manera, emerge el concepto de red como una noción recuperada por el capitalismo, útil para describir la vida social contemporánea, la cual hasta no hace mucho estaba relacionada con la

3 Estas nuevas posibilidades fomentan discusiones sobre cuánto cambian o se mantienen las sujeciones. Por ejemplo, ante la revolución que ha significado la tecnología en el campo reproductivo surgen diversas posturas desde los estudios de género, por un lado, se critica que la medicina controle científicamente el proceso de gestación incluso perpetuando la sospecha sobre la mujer y su cuerpo, esta es la postura de la autora feminista Yvonne Knibielher (citada en Le Breton 2002), por otro, se argumenta que, con los avances tecnológicos en la fecundación, la biografía normal se convierte en un proceso de autoconstrucción y de elección permanente cuya pluralidad de configuraciones familiares cuestionan a su vez el significado convencional del cuidado y las formas de patriarcado (Rivas, 2015). 
distribución de servicios u otros bienes, a las organizaciones clandestinas y al desarrollo de actividades ilícitas como el narcotráfico, y que ahora es empleada en las ciencias sociales para describir estructuras "escasamente - cuando no en absoluto - jerárquicas, flexibles y no limitadas por fronteras establecidas a priori”'(Boltanski y Chiapello, 2002, p.155), convirtiéndose en una nueva característica de socialización entre los individuos.

La vida social ya no se representa en forma de una serie de derechos y deberes como pudiese suceder en un mundo doméstico ni tampoco bajo la forma de trabajo asalariado inserto en una estructura jerárquica como ocurría en el mundo industrial - ampliamente criticado por los escépticos de la modernidad - sino que ahora "la vida social se compone de una multiplicación de encuentros y de conexiones, temporales y reactivables con grupos diversos, realizadas eventualmente a distancias sociales, profesionales, geográficas y culturales muy elevadas" (Boltanski y Chiapello, 2002, p.155). Justamente, es donde el proyecto constituye la oportunidad para forjar vínculos que permiten también la acumulación, la productividad y el reparto de todo cuanto pasa por ellos y cobra diversas formas.

A esta nueva lógica, a este nuevo sistema de valores, los autores han decidido denominar "ciudad por proyectos", atendiendo a una tradición proveniente del trabajo que realizan Boltanski y Thévenot (1991), quienes aluden a una cierta gramática de las ciudades según sus formas organizativas. Así, existirían o existieron la ciudad industrial, doméstica, comercial o de renombre y, finalmente, la ciudad por proyectos cuya forma operativa es la reticular.

\section{1- El mercado de la salud en un mundo en red}

Tal y como lo señalan Boltanski y Chiapello (2002) en "un mundo totalmente en red, no hay clausura posible" (p.158), pues la red se extiende y se modifica de forma constante sin que exista alguna razón para detenerse; por ello, la red sola no forma un sistema o ciudad, necesita alguna razón para iniciar y finalizar esa serie de vínculos y conexiones, es decir, algún proyecto. En este sentido, la salud y sus engranajes constituirían un espacio de cálculo que el mercado ha venido a conquistar, diversificar y transformar con propuestas novedosas que incluyen al cuerpo y es bajo este marco que surgen una serie de cambios profundos en la medicina que, según Conrad (2007) y sus estudios sobre medicalización, provienen desde tres ámbitos.

El primero de estos cambios es la biotecnología, donde se produce un desplazamiento de la medicina hacia la alteración, planificación y perfeccionamiento genético de la especie. Conrad (2007) explica que existe una gran demanda por el mejoramiento ya sea de los niños, sus cuerpos y sus habilidades mentales e incluso se perfila el mejoramiento genético de características corporales como: "la estatura, musculatura, forma o color; de habilidades como la memoria, la vista, el oído y la fuerza o en talentos y rendimiento físico" (p.137) ${ }^{1}$. Por tanto, la biotecnología sería uno de los nuevos actores de la medicina que vehiculiza una nueva forma de concebir lo corpóreo.

La emergencia de consumidores de salud es el segundo de los cambios, "debido a que el cuidado de la salud se ha mercantilizado y está sujeto a las fuerzas del mercado, la atención médica ha ampliado sus productos y servicios" (Conrad, 2007, p.138) ${ }^{2}$ y las instituciones del cuidado de la salud ahora compiten por los pacientes como consumidores. Un ejemplo de tal consumismo, en el mercado de la salud, es la cirugía cosmética en tanto sus modalidades (perfilamiento de nariz, implantes de silicona, liposucción, entre otros procedimientos) se han convertido en un gran negocio para la medicina.

El Internet también se ha convertido en un importante vehículo para el consumo de salud, pues por un lado, "todas las compañías farmacéuticas y clínicas tienen sitios digitales repletos de información para orientar a los consumidores" (Conrad, 2007, p.140) ${ }^{3}$, los cuales incluyen encuestas y preguntas para gestionar el tipo de tratamiento que requieren. Por otro, "hay miles de foros, salas de encuentro y páginas web donde los particulares pueden compartir información sobre enfermedades, tratamientos, quejas y servicios" (Conrad, 2007, p. 140) ${ }^{4}$, permitiendo así que la enfermedad sea transformada en una experiencia pública y que los usuarios se empoderen como consumidores de salud. Es decir, el consumidor 
se vuelve activo en su demanda, contribuyendo a su propia medicalización y cambiando el paradigma de la clásica relación médico-paciente.

Finalmente, el tercer cambio proviene del ámbito del cuidado de la salud, donde ahora se trata de empresas que lo administran. Lo que antes llevaban a cabo instituciones como el hospital, ahora son servicios del cuidado, las cuales no necesitan mantener al paciente recluido en un espacio territorial determinado e incluso sus gestiones se pueden llevar a cabo a la distancia. Los tres ámbitos coexisten y se agencian mutuamente, de hecho hay investigaciones que señalan que la biotecnología y la medicalización están cambiando las formas clásicas del cuidado, la salud y las relaciones de familia ${ }^{4}$.

Si se repara en estos tres cambios que advierte Conrad en la medicina moderna se constata que corresponden a los mismos tres ámbitos advertidos por Foucault en los inicios del despegue médico, antes mencionados, que son: la biohistoria, en este caso asociada a los mejoramientos genéticos; la medicalización, relacionada con toda la red de servicios y/o consumidores; y la economía de la salud, donde ya no hay instituciones y pacientes sino empresas y clientes. Es así como se puede trazar una línea de tiempo correlativa entre estos dos autores, la diferencia estriba en la funcionalidad del cuerpo en un modelo social y otro, el cual pese a haber cambiado pareciera seguir bajo control.

\section{2- De la socialización del cuerpo al cuerpo en red}

Si el desarrollo tecnológico ha producido modificaciones importantes en el mercado de la salud y la organización de sus servicios, entonces es menester decir que tales transformaciones han redefinido las relaciones sociales a diversas escalas, una de ellas es la que se produce entre los administradores de salud y los pacientes que ahora son considerados consumidores y/o usuarios de un servicio que se caracteriza por su trabajo en red, esto es, por la confluencia en el cuerpo de agenciamientos (objetos, personas, instituciones) provenientes de distintas lugares e intereses.

Por tanto, si Foucault advirtió la socialización del cuerpo como un primer desplazamiento de la medicina moderna, donde éste se ponía a disposición de una serie de instituciones y conocimientos que le producían, en la actualidad se asiste a la confluencia en el cuerpo de una serie de conexiones y vínculos por vía de la red que lo performan y permiten vislumbrarlo no sólo como materialidad sino como una red en sí misma.

En este sentido, Bruno Latour (2004) invita a despojarse de la definición patológica del cuerpo, a superarlo como esencia o sustancia y verlo más bien como "una interfaz que se vuelve cada vez más descriptible en tanto aprende a ser afectada por muchos más elementos" (p.2) ${ }^{5}$. Por tanto, el cuerpo no es una residencia provisional de algo superior - un alma inmortal, lo universal, o el pensamiento- sino que es una trayectoria dinámica que aprende a registrar y se vuelve sensible ante aquello de lo que el mundo está hecho.

Desde esta perspectiva, la interfaz, todo lo que implique una zona o soporte de comunicación, constituye un valor, pues pone en relación, crea vínculos, entre unos agenciamientos y otros. Y aunque esto no es algo novedoso, en el último tercio del siglo XX el arte de tejer y de utilizar los vínculos, más diversos y lejanos, se ha autonomizado (Boltanski y Chiapello, 2002) volviéndose un valor en sí. La tecnología multiplica las interfaces entre los usuarios de los servicios de salud y las empresas que los prestan, entre los pacientes y los médicos; mientras el cuerpo navega como imagen, como dato, como proyecto, resultado de una serie de relaciones que le afectan y performan.

Un ejemplo claro de este desplazamiento, de esta nueva forma de comprender y actuar sobre el cuerpo, son los servicios de teleasistencia, donde el cuidado se realiza a través de artefactos tecnológicos

4 Según Rivas (2015) surgen nuevas redes de modalidades familiares no convencionales, como las madres solteras por elección o padres solteros, así como nuevos proyectos y escenarios de procreación como lo son las técnicas de reproducción asistida entre las que se encuentran: la inseminación artificial, la fecundación in vitro, la gestación por sustitución, entre otras; que implican nuevos retos, para las instituciones y para los servicios. 
que permiten el control de una persona enferma. Según Sánchez (2012) los mecanismos de teleasistencia generan diferentes formas de distancia y cercanía, en las que se conjugan variados modos de ser y relacionarse, pues en lugar de llamar a una ambulancia o sus familiares, el usuario puede emitir señales a través de los dispositivos y recibir asistencia inmediatamente.

Así, el cuerpo ya no es sólo el lugar donde reside la enfermedad sino que también es un motivo y espacio para conectarse, establecer redes, en otras palabras, deviene como interfaz que afecta y es afectada. Además, el cuerpo en sí mismo puede ser una red, cuyos síntomas, órganos e imágenes ya no están ancladas a un territorio, esto es, ya no se derivan de la pertenencia a un lugar sino que funcionan como actores que atan y desatan vínculos y relaciones sociales, económicas y políticas.

\section{3- El cuerpo como proyecto}

Pese a todas las advertencias que se deban tener con la afirmación: "el cuerpo se ha convertido en proyecto, desde cambios leves a extremos, y la medicina es el vehículo para lograrlo" (Conrad, 2007, p.138 ${ }^{6}$, incluso se podría llegar a decir que todo el cuerpo ha sido medicalizado, cada una de sus piezas es un proyecto dentro de la red de medicalización. Pero, esto no se queda allí, las transformaciones del mundo reticular han venido a modificar los paradigmas científicos en general, impactando no sólo en el campo de la genética corporal sino también en su antropología.

Un claro ejemplo es el estudio del cáncer, el cual ha convocado el interés de múltiples comunidades y cuyos avances muestran que, en la actualidad, las enfermedades no conservan una materialidad anclada en los síntomas del cuerpo, sino que se transforman en proyecciones que provienen de trayectorias médicas, análisis genéticos, interpretación de imágenes de distintos especialistas en el mundo y así adquieren un nuevo carácter o, como lo expresan Castillo y Tirado (2012), un nuevo tipo de objetualidad.

Con esto se confirma que la experiencia de la enfermedad es una especie de vector que se trasmite y comunica mediante la red; por ende el cuerpo, en sí mismo, ya no está anclado en el territorio, ni su materialidad ni sus relaciones y ni siquiera sus enfermedades están sujetas al lugar físico donde se encuentra; cada vez es más adaptativo, flexible, con tendencia a modificaciones y objeto de planificación. De manera que, por cuenta de la biotecnología, mejoramiento genético, cirugías, telecuidado y también de la investigación científica de enfermedades en red, el cuerpo "ya no es un destino al que uno se abandona sino un objeto que se moldea a gusto" (Le Breton, 2002, p.156) y que se desvanece, nace y rehace en un mar de conexiones, cambiando sustantivamente la relación de conciencia del sujeto con respecto a sí mismo y los otros.

En el nuevo espíritu del capitalismo (Boltanski y Chiapello, 2002) se produce un cambio en la concepción de propiedad, y en particular de la concepción que se tiene sobre el cuerpo, generando un importante crecimiento de las industrias que tienen por objeto la producción de una imagen de sí mismo (moda, salud o cosmética). Se podría decir que con el nuevo espíritu del capitalismo la moral del cuerpo vuelve a mutar, ahora hacia el ideal de desarrollo personal, donde cada actor se produce a sí mismo.

\section{1- El empresario de sí: optimización y rendimiento corporal}

La idea del cuerpo-máquina siempre estuvo relacionada con el trabajo de la fábrica pero ahora ésta última ha sido reemplazada por la empresa, la cual no tiene cuerpo sino alma (Deleuze, 2005), y ya no funciona bajo el disciplinamiento sino con la motivación, lo que se traduce, en palabras de Bröckling (2015), en que cada uno debe arreglárselas para convertirse, hasta el último rincón de su alma, en un empresario de sí.

Tras un análisis de libros, que incluyen manuales de coaching, artículos de revistas y otros escritos sobre lo que se debe hacer para ser un emprendedor exitoso, Bröckling (2015) intenta establecer una gramática del gobernar y del gobernarse que no se mantiene en el campo empresarial, sino que permea la sociedad y como señala Nikolas Rose (2012) ha redefinido la práctica de la medicina en la actualidad. 
Al respecto, explica Rose (2012) que si bien el nacimiento de la clínica de Michel Foucault (1973) constituyó un análisis revolucionario puesto que reveló los modos en los que la enfermedad y la medicina se posaron sobre el cuerpo, hoy el hecho de que la propia medicina ha sido un objeto de transformación económica propicia nuevos enfoques y retos. Por ejemplo, actualmente el abordaje de la salud y la enfermedad son un territorio de cálculo en materia de rentabilidad corporativa, lo que conlleva a mirar la corporalidad no sólo como un depositario de disciplinamientos, sino como un ámbito con disposición agencial.

Tales cambios junto al surgimiento de nuevas tecnologías de la vida (Rose, 2012) generan nuevos modos de pensar y comprender las relaciones médicas y el cuerpo. Por ejemplo, el trasplante de órganos no se reduce al triunfo de la cirugía sino a un nuevo conjunto de relaciones sociales, nuevas ideas acerca de la vida, de la propiedad del cuerpo y del derecho a la cura, así como complejos engranajes financieros e institucionales que deben entenderse como "ensamblajes híbridos" (2012, p.49) orientados a la optimización del organismo.

Esta maraña o conjunto de ejes que se entretejen generando situaciones y experiencias concretas (Platero, 2012) recuerdan que el sujeto es un campo de batalla (Virno, 2003), pues no se trata ni de una víctima sumisa ni de una resistencia consciente, al poder, sino que es siempre un efecto (Bröckling, 2015) y es esta circunstancia la paradoja que le constituye. A la hipótesis del cuerpo como proyecto no sólo hay que agregar la advertencia del control sino también la de la autoconstitución, la identidad y el ejercicio del poder del propio sujeto.

\section{2- El desborde del proyecto. (De Beauvoir a Butler)}

La posibilidad de ejercer el poder por parte del sujeto sin duda alude a la significación y uso de su propio cuerpo en un proyecto que puede o no ser propio. Si el poder reside, se ejerce en el cuerpo, éste es también un espacio de resistencia. Al señalar que la mujer no nace sino que se hace, Beauvoir (1998) abre un conjunto de posibilidades entre el discurso y el cuerpo, e inicia el recorrido de la performatividad asociada al género. También desde Beauvoir, el cuerpo no es una cosa sino una situación, esto es, un conjunto de acciones posibilitadas o imposibilitadas por el contexto que, además, constituye para los seres el mejor de los proyectos.

Más recientemente, Butler (2002) explica, en el marco de la teoría de los actos de habla, que se considera performativa aquella práctica discursiva que realiza o produce lo que nombra. En este sentido, el cuerpo es construido discursivamente a través de su identificación plena con el sexo, es decir, es la visión dicotómica del cuerpo (hombre o mujer) la que crea la apariencia de sustancia, de una forma natural de ser.

A esta categorización o estilización del cuerpo, Butler la llama efecto del género (2007) y está anclada en una mirada totalmente jerárquica, dicotómica y heterosexual del cuerpo humano y de las relaciones sexuales (Esteban, 2006) que rara vez los avances de la medicina occidental están dispuestos a tensionar o integrar su complejidad. Los cuestionamientos a estas determinaciones provienen en su mayoría de la filosofía, las artes, los movimientos sociales; pero difícilmente del campo biomédico, el cual en todos sus avances y adelantos reproduce el modelo binario de $\operatorname{sexos}^{5}$.

No obstante, investigaciones en materia de reproducción parecen abrir nuevas posibilidades que no sólo desvinculan la sexualidad de la fecundación, sino que desbordan las capacidades de los cuerpos $^{6}$, erosionando, al menos hipotéticamente, el imaginario de hombre y mujer. Ahora bien, eso no

5 Este modelo de dos sexos, explica Esteban (2006), condiciona la manera de percibir médicamente los cuerpos y diagnosticar según hombres o mujeres, y viceversa; todo ello al margen de la experiencia individual de la identidad de género, la cual es mucho más diversa, híbrida y contradictoria. 
significa que se hayan superado las disparidades en torno al género, pues en caso de llegar a ser posible el embarazo tanto en hombres como mujeres, se estarían dejando intactas desigualdades relativas a las sexualidades no normativas (Platero, 2012).

Por ello, el desborde del proyecto va del orden simbólico a la puesta en escena de la vida cotidiana, en la posibilidad de reapropiarse (Butler, 2007) de ciertas normas y códigos para mostrar la debilidad o fragilidad de estructuras heterocentradas o normativas y, así, permitir que el cuerpo interpele aquello que no había sido nombrado.

\section{4- Conclusiones}

Más que concluir, el recorrido planteado se abre a nuevas interrogantes en torno a la relación cuerpo, salud y modernidad: ¿realmente se abandonó la idea del cuerpo como máquina en el campo médico para adoptar la de proyecto? ¿El cuerpo como proyecto es accesible a toda la sociedad?

Claramente no se puede hablar de una totalización de la idea de proyecto ni que éste sea accesible para todos por igual, pero sí del surgimiento de nuevos enfoques que lentamente van erosionando el paradigma disciplinar, asociado al cuerpo-máquina, y se trasladan hacia una gubernamentalidad mucho más sutil. Tampoco se puede decir que esto ocurre de igual manera en todas partes, debido a que los contextos plantean retos y significaciones diferentes al mismo problema, por ello la agenda actual de los estudios sobre el cuerpo está enfocada en los cruces que se producen entre políticas corporales y emociones, en el contexto actual de expansión global del capitalismo ${ }^{7}$.

Lo que sí muestra este recorrido es que así como Foucault advirtió la emergencia de una moral del cuerpo asociada a la higiene, la limpieza y la salud en el siglo XVIII, en la actualidad, Conrad, así como también Rose y Bröckling advierten una nueva moral corporal vinculada a la autogestión del bienestar, la mercantilización de la salud y los avances tecnológicos, donde cada cual es responsable de su cuerpo, de su imagen, de su éxito y de su destino.

De allí surge el vínculo con la tesis de Boltanski y Chiapello, pues en el nuevo espíritu del capitalismo los dispositivos han sido redefinidos en función de responder a las críticas que surgieron respecto al disciplinamiento de los cuerpos, por tanto, éste ya no puede ser objeto de constricción de circuitos cerrados, sino que su control ahora proviene de la introducción de nuevas modulaciones que puedan apaciguar las críticas a través de reivindicaciones.

Haciendo un paralelismo con Deleuze (2005) se puede decir que el desplazamiento del cuerpo como máquina al cuerpo como proyecto no es otro que el desplazamiento de la fábrica a la empresa; mientras la fábrica constituía a los individuos en cuerpos que conformaban una masa, la empresa opone a los individuos entre ellos y atraviesa a cada uno, por tanto, deben redefinirse constantemente, actualizarse, reinventarse y proyectar la imagen de sí mismos que mejor les permita competir.

Tampoco se puede obviar el potencial subversivo que tienen los mismos códigos del control. La idea del cuerpo como proyecto moviliza muchas luchas en contra del disciplinamiento sexual y determinismo biológico. Por ello, Butler (2007) advierte sobre un margen de intervención entre las palabras y sus efectos performativos como un espacio de resistencia y confrontación política en el interior de los discursos dominantes, el cual; sin embargo, debe tener la advertencia de que el mercado procesa de forma permanente las alteridades y esto se refleja, con rapidez, en todas sus extensiones.

7 Sobre el cuerpo en América Latina se recomienda revisar la recopilación de Scribano (2005), quien ofrece un estado del arte de lo publicado en el ámbito local. 


\section{Bibliografía}

Beauvoir, Simone. (1998). El segundo sexo. Madrid: Cátedra.

Boltanski, Luc. (1975). Los usos sociales del cuerpo. Buenos Aires: Periferia.

Boltanski, Luc y Chiapello, Eve. (2002). El nuevo espíritu del capitalismo. Madrid: Akal.

Boltanski, Luc y Thévenot, Laurent. (1991). De la justification. Les économies de la grandeur. Paris: Gallimard.

Bourdieu, Pierre. (2002). La distinción. Criterio y bases sociales del gusto. México: Taurus.

Bröckling, Ulrich. (2015). El self emprendedor. Sociología de una forma de subjetivación. Santiago de Chile: Ediciones Universidad Alberto Hurtado.

Butler, Judith. (2002). Cuerpos que importan. Buenos Aires: Paidós

Butler, Judith. (2007). El género en disputa. Barcelona: Paidós

Callon, Michel. (1998). Los mercados y la performatividad de las ciencias económicas. Apuntes de Investigación del Cecyp, 1 (14), 11-68. Recuperado de http://www.apuntescecyp.com.ar/index. php/apuntes/article/view/123

Castillo, Jorge y Tirado, Francisco. (2012). La nueva materialidad del cáncer. Teoría del actor-red y objetos potenciales. En Tirado, Francisco y López, Daniel. (Eds.), Teoría del actor-red. Más allá de los estudios de ciencia y tecnología. Barcelona: Amentia Editorial.

Conrad, Peter. (2007). The medicalization of society. Baltimore: The Johns Hopkins University Press.

Deleuze, Gilles (2005). Posdata sobre las sociedades de control. En Ferrer, Christian. (Comp.), El lenguaje libertario: antología del pensamiento anarquista contemporáneo (pp. 115-121). La Plata: Terramar.

Esteban, Mari Luz. (2006). El estudio de la salud y el género: las ventajas de un enfoque antropológico y feminista. Salud Colectiva, 2 (1), 9-20

Foucault, Michel. (1996). La vida de los hombres infames. La Plata: Altamira.

Foucault, Michel. (2008a). Las palabras y las cosas. Buenos Aires: Siglo XXI.

Foucault, Michel. (2008b). El Nacimiento de la clínica. Buenos Aires: Siglo XXI.

Foucault, Michel. (2008c). Vigilar y Castigar. Buenos Aires: Siglo XXI.

Fuster, Nicolás. (2013). El cuerpo como máquina: la medicalización de la fuerza de trabajo en Chile. Santiago de Chile: Ceibo.

Goffman, Erving. (2008). Estigma, la identidad deteriorada. Buenos Aires: Amorrortu.

Knibielher, Yvonne. (19, abril, 1985). La maternité sous controle [La maternidad bajo control]. Le Monde. En Le Breton, David (2002). Antropología del cuerpo y modernidad. Buenos Aires: Nueva Visión.

Kundera, Milan. (1996). La insorportable levedad del ser. Barcelona: Tusquets Editores.

Latour, Bruno. (2004). How to talk about the body? The normative dimension of science studies [¿Cómo hablar sobre el cuerpo? La dimensión normativa de los estudios científicos]. Body and Society, $10(2 / 3)$ 205-229

Le Breton, David. (2002). Antropología del cuerpo y modernidad. Buenos Aires: Nueva Visión.

Ortega, Fernando. (2010). El cuerpo incierto: corporeidad, tecnologías médicas y cultura contemporánea. Madrid: Consejo Superior de Investigaciones Científicas.

Platero, Raquel (Lucas). (2012). Intersecciones: cuerpos y sexualidades en la encrucijada. Barcelona: Ediciones Bellaterra.

Rivas, Ana María. (2015). Revisitando el parentesco: ¿sigue siendo la sangre más espesa que el agua? Nuevas formas de parentesco y familia. En Gonzálvez, Herminia (Edit.) Diversidades familiares, cuidados y migración. Santiago: Editorial Universidad Alberto Hurtado.

Rose, Nikolas. (2012). Políticas de la vida: biomedicina, poder y subjetividad en el siglo XXI. La plata: UNIPE: Editorial Universitaria. 
Sánchez, Tomás. (2012).¿Cómo se mantiene una usuaria? Prácticas de apuntalamiento en la teleasistencia para personas mayores. En Tirado, Francisco y López, Daniel. (Eds.), Teoría del actor-red. Más allá de los estudios de ciencia y tecnología. Barcelona: Amentia Editorial.

Scribano, Adrián. (2015). Los estudios sociales sobre cuerpos y emociones en Argentina: un estado del arte. Buenos Aires: Estudios Sociológicos.

Virno, Paolo. (2003). Gramática de la multitud. Para un análisis de las formas de vida contemporánea. Buenos Aires: Ediciones Colihue. 
